\title{
General Internists Versus Specialists as Attendings for General Internal Medicine Inpatients at a Canadian Hospital: a Cohort Study
}

\author{
Anthony D. Bai, MD ${ }^{1}$, Siddhartha Srivastava, MD, MSc ${ }^{1,2}$, Christopher A. Smith, MBBS ${ }^{1,2}$, and \\ Sudeep S. Gill, MD, MSc $c^{1,2,3}$ \\ 'Department of Medicine, Queen's University, Kingston, Ontario, Canada; ${ }^{2}$ Kingston General Hospital, Kingston, Ontario, Canada; ${ }^{3}$ Providence \\ Care Hospital, Kingston, Ontario, Canada.
}

KEY WORDS: general internal medicine; general internists; quality of care.

J Gen Intern Med 33(11):1848-1850

DOI: $10.1007 / \mathrm{s} 11606-018-4585-5$

() Society of General Internal Medicine 2018

\section{INTRODUCTION}

Both general internists and specialists serve as attending physicians on general internal medicine (GIM) wards in hospitals. ${ }^{1,2}$ As attending physicians on GIM wards, specialists often care for patients with conditions outside their domain of expertise, which may lead to differences in efficiency and quality of care compared to general internists. ${ }^{3}$ This study's objective was to examine the relationship between receipt of care from general internists versus specialists as attending physicians and outcomes including hospital length of stay (LOS), readmissions, and inpatient mortality.

\section{METHODS}

We conducted a retrospective cohort study at Kingston General Hospital, a large Canadian tertiary care hospital. Consecutive adult patients admitted to GIM wards from January 1, 2015, to January 1, 2016, were included. Patient data were obtained from patient electronic medical records and the discharge abstract database.

Attending physician was the main responsible physician for the GIM inpatient at time of discharge or death. A general internist was defined as a faculty member of the GIM division with a practicing license listed as GIM or internal medicine without subspecialty whose main responsibilities included GIM ward service and GIM outpatient clinics. A specialist was defined as a faculty member of an internal medicine subspecialty division with a practicing license listed as subspecialty whose main responsibilities included subspecialty inpatient consult service and subspecialty outpatient clinics.

Patient outcomes included hospital LOS, readmission, and all-cause in-hospital mortality. LOS was compared using the Wilcoxon signed-rank test. Readmission and mortality rates were compared using Fisher's exact test.

As a secondary analysis, propensity score matching based on patient baseline characteristics was used to improve

Published online July 26, 2018 comparability between patients under general internists and those under specialists. The two propensity-matched groups were compared in terms of LOS, readmission, and in-hospital mortality as described above.

\section{RESULTS}

\section{Attending Physicians}

From January 1, 2015, to January 1, 2016, 34 staff physicians attended on the 4 GIM teams, including $9(26 \%)$ general internists and $25(74 \%)$ specialists (Table 1).

\section{Patient Outcomes}

Of the 3782 consecutive GIM inpatients, 1747 (46\%) and $2035(54 \%)$ received care from general internists and specialists respectively (Table 2 ).

The median LOS was 4.89 (IQR 2.62-9.52) days for patients under general internists and 5.25 (IQR 2.7510.28) days for those under specialists $(p=0.049)$. Of the 3516 discharges, $667(19 \%)$ patients were readmitted within 30 days: $326 / 1634(20 \%)$ discharged by general internists and $341 / 1882(18 \%)$ discharged by specialists $(p=0.17)$. During their hospital stay, $266(7 \%)$ patients died: 113/1747 (6\%) patients under general internists and $153 / 2035(8 \%)$ under specialists $(p=0.23)$.

\section{Secondary Analysis}

Using propensity scores, 1339 patients under general internists were matched to 1339 patients under specialists (Table 2). There was excellent balance on a large number of baseline characteristics (standardized differences for these characteristics were all $<10 \%)$.

The median LOS was 4.98 (IQR 2.63-9.71) days for patients under general internists and 5.41 (IQR 2.85$10.77)$ days for those under specialists $(p=0.04)$. Of the discharges, 259/1250 (21\%) patients discharged by general internists and 236/1241 (19\%) patients discharged by specialists were readmitted to the hospital within 30 days $(p=0.29)$. During their hospital stay, $89 / 1339(7 \%)$ patients under general internists and 98/1339 (7\%) under specialists died $(p=0.54)$. 
Table 1 Characteristics and Outcomes of General Internist and Specialist Attending Physicians

\begin{tabular}{|c|c|c|c|}
\hline & General internists $(N=9)$ & Specialists $(N=25)$ & $P$-value \\
\hline Male, $N(\%)$ & $4(44 \%)$ & $17(68 \%)$ & 0.25 \\
\hline \multicolumn{3}{|l|}{ Years post graduation, $N(\%)$} & 0.06 \\
\hline $0-10$ years & $6(67 \%)$ & $5(20 \%)$ & \\
\hline $11-20$ years & $1(11 \%)$ & $9(36 \%)$ & \\
\hline$>20$ years & $2(22 \%)$ & $11(44 \%)$ & \\
\hline \multirow[t]{8}{*}{ Specialty, $N(\%)$} & GIM, $9(100 \%)$ & Pulmonary, 6 (24\%) & \\
\hline & & Nephrology, $4(16 \%)$ & \\
\hline & & Intensive care, 3 (12\%) & \\
\hline & & Cardiology, $3(12 \%)$ & \\
\hline & & Endocrinology, 3 (12\%) & \\
\hline & & Rheumatology, 3 (12\%) & \\
\hline & & Gastroenterology, 2 (8\%) & \\
\hline & & Allergy, $1(4 \%)$ & \\
\hline Weeks on GIM ward in study year, median (IQR) & $11(7-13)$ & $4(2-6)$ & $<0.001$ \\
\hline \multicolumn{4}{|l|}{ Deaths in hospital } \\
\hline Rate of deaths $/ 100$ patient days & 0.96 & 0.98 & \\
\hline Unadjusted IRR (95\% CI) & $0.98(0.76-1.25)$ & Reference & 0.87 \\
\hline Adjusted IRR $(95 \% \mathrm{CI})^{*}$ & $0.87(0.60-1.24)$ & Reference & 0.44 \\
\hline \multicolumn{4}{|l|}{ Discharges from hospital } \\
\hline Rate of discharges $/ 100$ patient days & 14.22 & 12.42 & \\
\hline Unadjusted IRR (95\% CI) & $1.14(1.07-1.22)$ & Reference & $<0.001$ \\
\hline Adjusted IRR $(95 \%$ CI)* & $1.11(1.01-1.22)$ & Reference & 0.03 \\
\hline
\end{tabular}

GIM, general internal medicine; IRR, incidence rate ratio

*Adjusted incidence rate ratio is estimated using a multivariable Poisson regression model that includes physician specialty (general internist versus specialist) along with other physician characteristics including sex, years post graduation, and number of weeks on GIM ward

\section{DISCUSSION}

In this study, GIM inpatients under the care of general internists had a modestly shorter LOS relative to those under the care of specialists without significant differences in readmissions or mortality. These results complement and extend findings of an earlier study that showed shorter LOS for GIM inpatients receiving care from general internists as compared to endocrinologists and rheumatologists. ${ }^{2}$

Study limitations include possible residual confounding from not adjusting for disease severity. As well, our study used data from a single academic acute care hospital, which may limit the generalizability of the results.
General internists may provide more efficient care because of their greater familiarity with inpatient GIM wards and related hospital processes. Note that general internists made up only $26 \%$ of the physicians in this study but provided care to $46 \%$ of GIM ward patients. Their experience may help expedite work-up, procedures, consultations with other specialty services, and collaboration with the interdisciplinary team for discharge planning, resulting in shorter LOS.

In conclusion, our study findings endorse the value of general internists for hospital GIM, which may not be replaceable by other internal medicine specialists.

Table 2 Baseline Characteristics of Patients Under General Internists and Specialists

\begin{tabular}{|c|c|c|c|c|c|c|}
\hline & \multicolumn{3}{|l|}{ All patients } & \multicolumn{3}{|c|}{ Patients matched by propensity score } \\
\hline & $\begin{array}{l}\text { General internists } \\
(N=1747)\end{array}$ & $\begin{array}{l}\text { Specialists } \\
(N=2035)\end{array}$ & Std. diff & $\begin{array}{l}\text { General internists } \\
(N=1339)\end{array}$ & $\begin{array}{l}\text { Specialists } \\
(N=1339)\end{array}$ & Std. diff \\
\hline Male & $878(50 \%)$ & $1050(52 \%)$ & 0.03 & $687(51 \%)$ & $682(51 \%)$ & 0.007 \\
\hline Age, median (IQR) & $71(58-82)$ & $71(57-81)$ & 0.04 & $71(59-82)$ & $71(57-81)$ & 0.05 \\
\hline Admission on weekend & $438(25 \%)$ & $544(27 \%)$ & 0.04 & $329(25 \%)$ & $344(26 \%)$ & 0.03 \\
\hline \multicolumn{7}{|l|}{ Charlson Comorbidity Index } \\
\hline 0 & $480(27 \%)$ & $585(29 \%)$ & 0.03 & $374(28 \%)$ & $404(30 \%)$ & 0.05 \\
\hline 1 & $406(23 \%)$ & $440(22 \%)$ & 0.04 & $312(23 \%)$ & $271(20 \%)$ & 0.07 \\
\hline$\geq 2$ & $861(49 \%)$ & $1010(50 \%)$ & 0.007 & $653(49 \%)$ & $664(50 \%)$ & 0.02 \\
\hline \multicolumn{7}{|l|}{ Top 7 admitting diagnoses } \\
\hline COPD & $176(10 \%)$ & $190(9 \%)$ & 0.02 & $134(10 \%)$ & $126(9 \%)$ & 0.02 \\
\hline Viral/unspecified pneumonia & $97(6 \%)$ & $133(7 \%)$ & 0.04 & $71(5 \%)$ & $77(6 \%)$ & 0.02 \\
\hline Lower urinary tract infection & $79(5 \%)$ & $91(4 \%)$ & 0.002 & $64(5 \%)$ & $57(4 \%)$ & 0.03 \\
\hline Heart failure without cardiac catheter & $68(4 \%)$ & $75(4 \%)$ & 0.01 & $51(4 \%)$ & $55(4 \%)$ & 0.02 \\
\hline Renal failure & $58(3 \%)$ & $60(3 \%)$ & 0.02 & $43(3 \%)$ & $49(4 \%)$ & 0.02 \\
\hline Gastrointestinal hemorrhage & $51(3 \%)$ & $59(3 \%)$ & 0.001 & $38(3 \%)$ & $39(3 \%)$ & 0.004 \\
\hline Diabetes & $59(3 \%)$ & $46(2 \%)$ & 0.07 & $39(3 \%)$ & $34(3 \%)$ & 0.02 \\
\hline
\end{tabular}

COPD, chronic obstructive pulmonary disease; Std. diff, standardized difference

The propensity score matched groups were also matched on admission months, general internal medicine teams, individual Charlson comorbidity score items, and the top 52 most common admitting diagnoses. These variables are not shown in the table 
Acknowledgments: Parts of this manuscript are based on data and information compiled and provided by the Canadian Institute for Health Information (CIHI). However, the analyses, conclusions, opinions, and statements expressed herein are those of the authors and not necessarily those of CIHI. No endorsement by CIHI is intended or should be inferred. We are indebted to Rod Albrough who extracted the data from the hospital database.

Corresponding Author: Sudeep S. Gill, MD, MSc; Providence Care Hospital, 752 King Street West, Kingston, Ontario K7L 4X3, Canada (e-mail: sudeep.gill@ices.on.ca).

\section{Compliance with Ethical Standards:}

Conflict of Interest: AD Bai: None to declare.

S Srivastava: None to declare.

CA Smith: CA Smith was one of the general internists included in this study.

SS Gill: None to declare.

\section{REFERENCES}

1. Hauer KE, Wachter RM, McCulloch CE, Woo GA, Auerbach AD. Effects of hospitalist attending physicians on trainee satisfaction with teaching and with internal medicine rotations. Arch Intern Med. 2004;164(17):1866-71.

2. Parekh V, Saint S, Furney S, Kaufman S, McMahon L. What effect does inpatient physician specialty and experience have on clinical outcomes and resource utilization on a general medical service?. J Gen Intern Med. 2004; 19(5p 1):395-401.

3. Weingarten SR, Lloyd L, Chiou CF, Braunstein GD. Do subspecialists working outside of their specialty provide less efficient and lower-quality care to hospitalized patients than do primary care physicians?. Arch Intern Med. 2002;162(5):527-32. 